\title{
Aplikasi Rekomendasi Rumah Makan Menggunakan Algoritma K-Nearest Neighbour Berbasis Android (Studi kasus: Kecamatan Banyuwangi)
}

\author{
Edo Ardhiansyah¹, Setio Basuki ${ }^{2}$, Galih Wasis Wicaksono ${ }^{3}$ \\ 1,2,3 Teknik Informatika/Universitas Muhammadiyah Malang \\ edoardhiansyah@gmail.com ${ }^{* 1}$, setio_basuki2@yahoo.co.id ${ }^{2}$, Galih.w.w@umm.ac.id ${ }^{3}$
}

\begin{abstract}
Abstrak
Banyak wisatawan yang silih berganti datang ke Kota Banyuwangi untuk berwisata alam, budaya, maupun kuliner. Banyak pengusaha yang mulai menggeluti bisnis rumah makan karena banyaknya wisatawan yang datang. Semakin menjamurnya bisnis rumah makan di kota Banyuwangi membuat menu makanan yang disajikan beraneka ragam. Tentunya akan membuat kebingungan untuk memilih rumah makan mana yang ingin dikunjungi. Dari permasalahan tersebut, peneliti membuat sebuah aplikasi sistem rekomendasi untuk menentukan pencarian lokasi makan berdasarkan kategori kisaran harga, makanan berkuah, digoreng, dibakar, makanan tradisional Banyuwangi, dan lain-lain. Diimplementasikan menggunakan teknologi android yang semakin memudahkan dalam mengakses aplikasi ini. Aplikasi ini dapat mempermudah pencarian lokasi, karena adanya fasilitas Google Maps API yang dapat menunjukkan titik koordinat lokasi. Dalam penelitian ini, rekomendasi untuk mencari rumah makan akan menggunakan Algoritma K-Nearest Neighbor (K-NN).
\end{abstract}

Kata Kunci: K-Nearest Neighbour, Google Maps, Global Positioning System

\begin{abstract}
Many tourists come and go to Banyuwangi City for nature, culture, and culinary trip. Many entrepreneurs are starting to cultivate the restaurant business because of the large number of tourists who come. The proliferation of restaurant business in the city of Banyuwangi make the food menu is presented variously. Surely it will create confusion to choose which restaurants to visit. From the problem, the researcher made a recommendation system application to determine the location search for food based on price range category, food sauce, fried, baked, traditional food of Banyuwangi, and others. Implemented using android technology that makes it easier to access this application. This app can make location search easier, because of the Google Maps API facility that can show the location coordinate point. In this study, recommendations for finding restaurants will use the K-Nearest Neighbor (K-NN) Algorithm.
\end{abstract}

Keywords: K-Nearest Neighbour, Google Maps, Global Positioning System

\section{Pendahuluan}

Sekarang ini kota Banyuwangi telah menjadi kota wisata. Banyak wisatawan yang silih berganti datang ke Kota Banyuwangi untuk berwisata alam, budaya, maupun kuliner. Sehingga membuat banyak pengusaha yang menggeluti bisnis dalam bidang rumah makan karena banyaknya wisatawan yang datang. Bisnis dalam bidang rumah makan masih diyakini sebagai salah satu peluang bisnis yang sangat bagus. Ini dibuktikan dari meningkatnya perkembangan usaha di bidang ini dari masa ke masa. Semakin menjamurnya bisnis rumah makan di kota Banyuwangi tentunya menu makanan yang disajikan beraneka ragam [1].

Hal tersebut akan berdampak kepada masyarakat maupun wisatawan yang suka melakukan wisata kuliner. Tentunya mereka akan kebingungan untuk memilih rumah makan mana yang akan dikunjungi karena semakin banyaknya ragam rumah makan. Namun pesatnya perkembangan teknologi internet serta teknologi elektronik yang bertambah murah (seperti tablet, smartphone, dan lain-lain). Tentu dapat membantu masyarakat maupun wisatawan untuk mencari lokasi atau tempat makan yang sesuai keinginannya. Dalam keadaan tersebut tentu 
dibutuhkan sebuah sistem rekomendasi yang mampu memberikan prediksi rekomendasi untuk mencari rumah makan [2].

Penelitian mengenai sistem rekomendasi untuk mencari rumah makan yang serupa pernah dilakukan sebelumnya. Prototype sistem rekomendasi rumah makan memakai metode $K$ Nearest Neighbour Berbasis Web, sistem rekomendasi ini mengunakan metode collaborative filtering pendekatannya menggunakan algoritma k-Nearest Neighbour (k-NN), proses rekomendasi pada sistem ini adalah mencocokan kemiripan karakteristik user peminta rekomendasi dengan user calon perekomendasi. Karakteristik yang dicocokan adalah nama, jenis kelamin, hobi, makanan favorit, pekerjaan, status hubungan, genre music, genre film, kota lahir dan kota tinggal [1]. Sistem rekomendasi restoran dengan pendekatan ektraksi fitur rasa pada menu makanan. Sistem menggunakan pendekatan dengan mempresentasikan menu yang memakai set atribut rasa yaitu lima macam rasa dasar asam, gurih, asin, pahit, dan manis [2]. Sistem rekomendasi pencarian rumah makan di Yogyakarta dengan metode kolaboratif, pada sistem ini menggunakan pendekatan tempat makan berdasarkan penilaian user lain didalam radius tertentu dari tempat user berada [3]. Perbedaan penelitian yang mau dikerjakan dengan beberapa penelitian yang sudah dikerjakan sebelumnya adalah studi kasus penelitian berada di kota Banyuwangi. Aplikasi diimplementasikan menggunakan teknologi android.

Berdasarkan masalah tersebut maka pada pengerjaan tugas akhir ini, penulis mengusulkan suatu aplikasi yang membuat sistem rekomendasi untuk menentukan pencarian lokasi makan berdasarkan kategori kisaran harga, makanan berkuah, digoreng, dibakar, makanan tradisional Banyuwangi, dan lain-lain. Diimplementasikan menggunakan teknologi android yang semakin memudahkan dalam mengakses aplikasi ini. Aplikasi ini dapat mempermudah pencarian lokasi, karena adanya fasilitas Google Maps API yang dapat menunjukkan titik koordinat lokasi. Dalam penelitian ini, rekomendasi untuk mencari rumah makan akan memakai Algoritma K-Nearest Neighbor (K-NN), karena algoritma ini sederhana, bekerja berdasarkan jarak terdekat dan mendapatkan data yang lebih akurat.

\section{Metode Penelitian}

\subsection{Studi Pustaka}

Dalam penelitian ini, penulis melakukan studi pustaka dari berbagai literatur termasuk dari buku, makalah-makalah, artikel ilmiah, maupun bahan-bahan dari internet yang sesuai dengan penelitian ini. Sumber pustaka digunakan untuk memahami konsep algoritma $K$-Neareast Neighbour yang akan di aplikasikan pada platform android.

\subsection{Analisa Kebutuhan}

Kebutuhan sistem yang dirancang sangat ditentukan berdasarkan wawancara kepada calon pengguna. Calon pengguna aplikasi merupakan masyarakat umum meliputi orang dewasa, mahasiswa, maupun pelajar yang menggunakan smart phone. menurut survei yang telah dilakukan maka didapatkan informasi bahwa pengguna sebagian besar menggunakan smartphone bersistem operasi Android.

\subsection{Perancangan Sistem}

Proses ini difokuskan pada pembuatan interface pada perangkat lunak, apabila interface sudah dibuat maka akan memudahkan untuk diimplementasikan pada tahap pembuatan program. Desain interface yang dibuat nantinya akan didokumentasikan agar pengerjaannya bisa di monitoring. Selanjutnya desain interface ditranslasikan pada perangkat lunak. Hasil akhir dari beberapa tahap yang dilakukan akan menghasilkan sebuah aplikasi.

\subsection{Implementasi}

Pada tahap ini Aplikasi akan dikerjakan memakai Android Studio dan juga Bahasa Pemrograman Java. Google Maps API akan digunakan sebagai layanan untuk menampilkan peta. Sedangkan untuk koneksi database memakai Bahasa pemrograman PHP. Untuk sistem dalam manajemen database akan menggunakan MySQL. Aplikasi pengembang dalam bahasa pemrograman PHP dikerjakan menggunakan Notepad++.

\subsection{Pengujian}

Pengujain ini dilakukan untuk mengetahui apakah hasil dari perancangan dan implementasi sudah berjalan sesuai dengan penelitian yang dibuat.

REPOSITOR, Vol. 2, No. 2, Februari 2020: 145-154 
3. Analisa Dan Perancangan Sistem

\subsection{Arsitektur Sistem}

Pada Gambar 1 dijelaskan secara singkat mengenai sistem yang akan dibuat, berikut adalah arsitektur dari program yang akan dirancang.

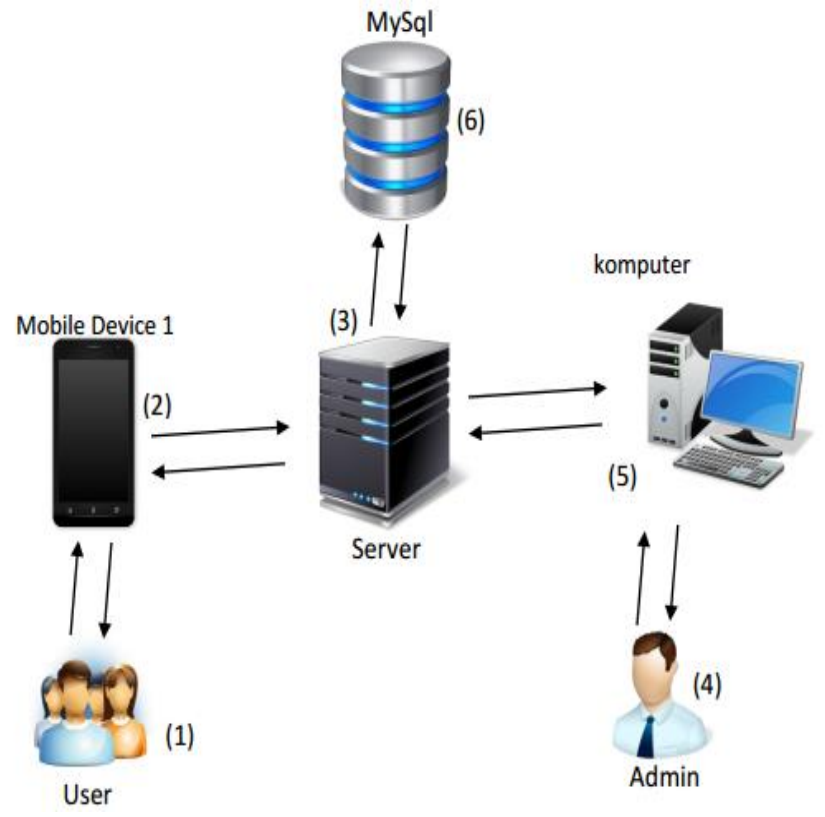

Gambar 1. Arsitektur Sistem

Berikut penjelasan skema arsitektur berdasarkan Gambar 1:

1. User, berperan sebagai client. User menginputkan kategori makanan melalui mobile device. Selain itu, user dapat melihat menu makanan dan lokasi rumah makan.

2. Mobile Device, bertugas mengirimkan segala request yang dilakukan oleh user kepada server.

3. Web Server, bertindak sebagai portal terhadap segala request, baik request dari mobile device maupun computer admin. Tugas dari server adalah menjembatani request dengan basis data.

4. Admin, bertugas untuk mengedit, menambahakan, dan menghapus data rumah makan.

5. Computer, bertugas untuk mengirimkan segala request yang berkaitan dengan mengedit, menambahakan, dan menghapus data rumah makan.

6. Server, bertugas untuk menyimpan segala request yang dikirimkan melalui web server. Basis data juga dapat mengirimkan data yang diminta oleh mobile device ataupun computer.

\subsection{Usecase Diagram}
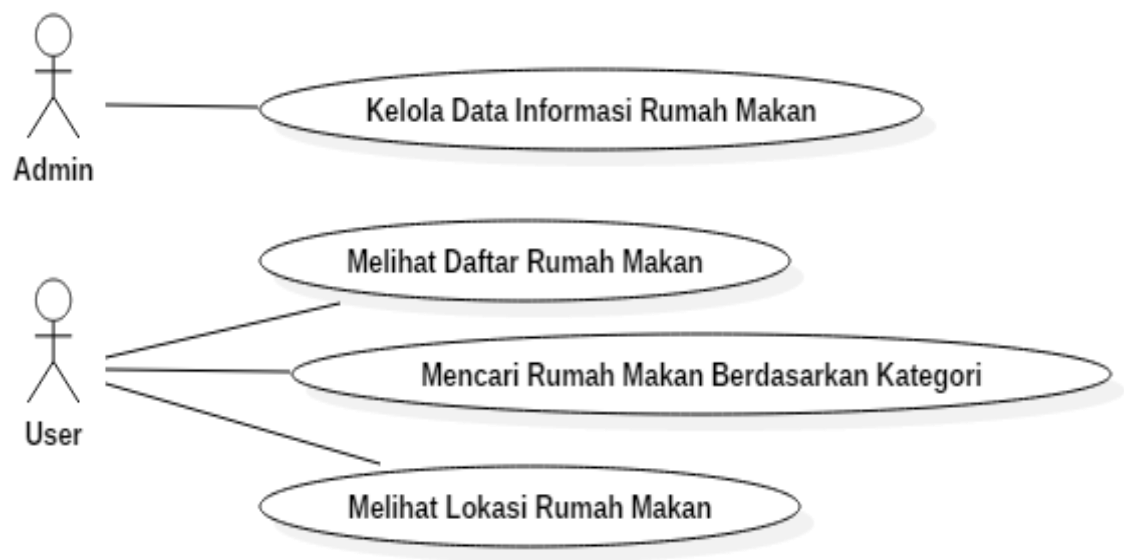

Gambar 2. Use Case Diagram

Aplikasi Rekomendasi Rumah Makan Menggunakan... Edo Ardhiansyah, Setio Basuki, Galih Wasis Wicaksono 
Berikut penjelasan Usecase Diagram berdasarkan Gambar 2:

1. Admin

- Kelola data informasi rumah makan Admin dapat mengedit, menambahkan atau menghapus data informasi rumah makan.

2. User

- Melihat daftar tumah makan User melihat seluruh data rumah makan di aplikasi ini.

- Mencari rumah makan berdasrkan kategori User memilih kategori makanan yang akan diproses mesin rekomendasi yang menggunkan algoritma K-Nearest Neighbor.

- Melihat lokasi rumah makan User dapat melihat seluruh lokasi rumah makan.

\subsection{Sistem Rekomendasi}

Sistem rekomendasi sudah digunakan oleh hampir semua area bisnis dimana seseorang memerlukan sebuah informasi agar mudah mengambil suatu keputusan. Sistem rekomendasi ini adalah model aplikasi berdasarkan hasil yang didapat ketika melakukan observasi pada keadaan dan kebutuhan user [4].

\subsection{K-Nearest Neighbour}

K-Nearest Neighbour (KNN) merupakan kelompok instance based learning. Algoritma KNN juga termasuk salah satu teknik dalam lazy learning. KNN bekerja dengan cara mencari k objek yang terdapat di dalam data training terdekat dengan objek yang ada pada data testing (data baru). Algoritma $K$-Nearest Neighbor adalah sebuah metode klasifikasi suatu objek berdasar data pembelajaran yang jaraknya terdekat dengan objek tersebut [5].

Langkah-langkah menghitung metode KNN adalah:

1. Ditetapkan jumlah $\mathrm{k}$ (jumlah tetangga terdekat).

2. Dihitung jarak kuadrat euclidean objek pada data training yang diberikan.

3. Diurutkan hasil pada langkah no 2 secara ascending.

4. Dikelompokkan kategori Y.

5. Dengan cara menggunakan kategori nearest neighbour akan dicari paling terdekat maka dapat dipredisikan kategori objek.

\subsection{Android}

Menurut Kurniawan Teguh Martono \& Oky Dwi Nurhayati Android yaitu salah satu Operation system yang dimiliki oleh telepon pintar. Sistem yang mempunyai basis linux dirancang untuk perangkat pintar seperti telepon pintar memungkinkan perangkat lunak untuk dimodifikasikan secara bebas dan didistribusikan oleh pembuat perangkat operator nirkabel dan pengembang aplikasi. Pengembangan aplikasi yang memperluas fungsionalitas perangkat, umumnya ditulis dalam versi custom bahasa pemrograman Java [6].

\subsection{GPS (Global Positioning System)}

Global Positioning System (GPS) merupakan layanan sistem untuk mensingkronisasi sinyal pada satelit dalam penentuan sebuah posisinya. Dengan adanya sebuah GPS (Global Positioning System) seseorang bisa mengetahui keberadaannya secara realtime maupun sebuah benda atau objek yang memakai sensor GPS [7].

\subsection{Google Maps API (Application Programming Interface)}

Menurut Gabriel Svennerberg (2010) Google Maps API adalah tool atau library dari Google untuk menampilkan peta digital di website, penggunaan Google Maps di website dapat melalui pemrograman [8].

\subsection{MySQL (My Structure Query Language)}

MySQL (My Structure Query Language) merupakan sebuah database yang menerapkan SQL (Structured Query Language). MySQL pada saat beroperasi secara client-server dengan memanfaatkan server daemon MySQL pada sebuah sisi server dan berbagai program yang berjalan pada sisi client [9].

REPOSITOR, Vol. 2, No. 2, Februari 2020: 145-154 


\subsection{JSON (Java Script Object Notation)}

Menurut Chasseur, Craig., Li, Y. dan Patel, Jm (2013) JSON (Java Script Object Notation) adalah format pertukaran data yang bersifat ringan, disusun oleh Douglas Crockford. JSON dirancang untuk memudahkan pertukaran data pada situs dan merupakan perluasan dari fungsifungsi javascript [10].

\section{Hasil Penelitian dan Pembahasan}

\subsection{Implementasi}

Implementasi merupakan proses penerapan dari hasil rancangan ke program yang telah dibuat kedalam sebuah aplikasi. Kegiatan implementasi dilakukan berpedoman pada dasar yang telah direncanakan dalam tahap perancangan.

\subsubsection{Tampilan Menu Halaman Utama}

Menu halaman utama pada Gambar 3 ini menampilkan pilihan semua menu yang meliputi Daftar Rumah Makan, Kategori Makanan dan Lokasi.

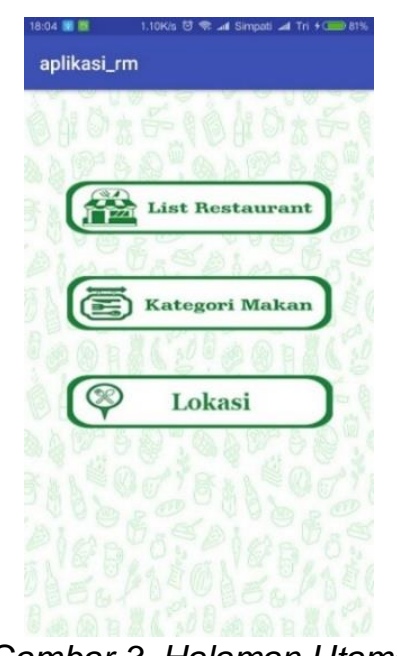

\section{Gambar 3. Halaman Utama}

\subsubsection{Tampilan Menu Daftar Rumah Makan}

Menu Daftar Rumah Makan Gambar 4 ini menampilkan sekuruh rumah makan yang ada pada aplikasi. Pada menu ini, ketika user menekan salah satu rumah makan. Maka akan tampil menu makanan dan minuman yang ada pada rumah makan yang dipilih dan ketika user menekan tombol lokasi makan akan menampilkan posisi rumah makan tersebut.

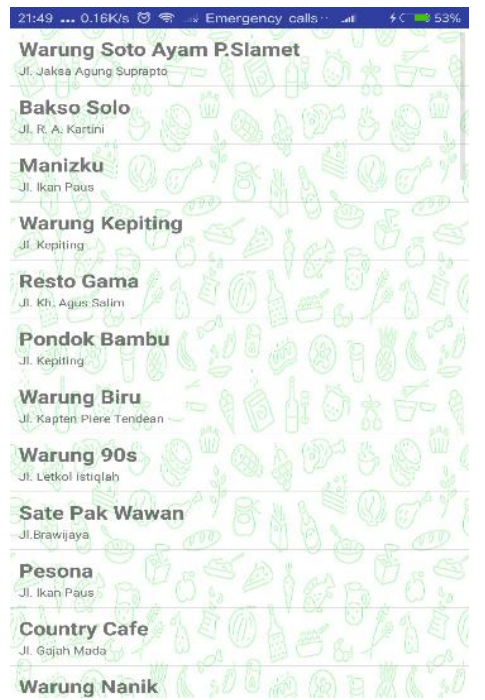

Gambar 4. Menu Daftar Rumah Makan 


\subsubsection{Tampilan Menu Kategori Makanan}

Menu Kategori Makanan Gambar 5 ini menampilkan harga dan kategori makanan yang dicari. Pada menu ini, user memasukan harga makanan yang dicari dan memilih beberapa kategori makanan. Ketika user menekan pada tombol proses maka akan sistem akan secara otomatis menghitung kedekatan dengan menggunakan algoritma $K$-Nearest neighbour yang kemudian akan menampilkan Menu Rekomendasi rumah makan yg cocok dengan pilihan user.

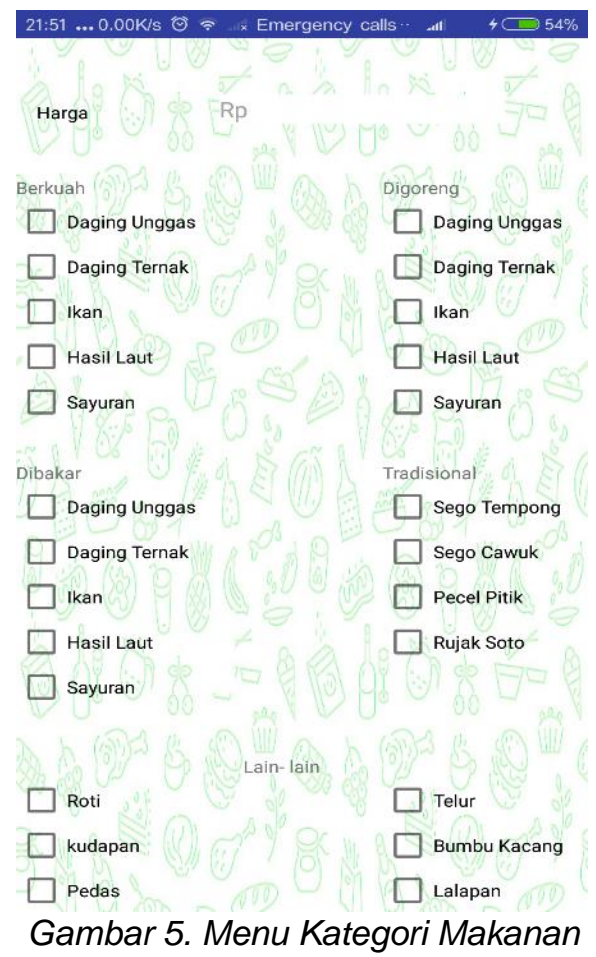

\subsubsection{Tampilan Hasil Rekomendasi}

Menu hasil rekomendasi Gambar 6 ini menampilkan rekomendasi rumah makan yang dicari. Pada menu ini, merupakan hasil proses rekomendasi rumah makan setelah sebelumnya pada menu kategori user memasukan harga makanan dan memilih beberapa kategori makanan.

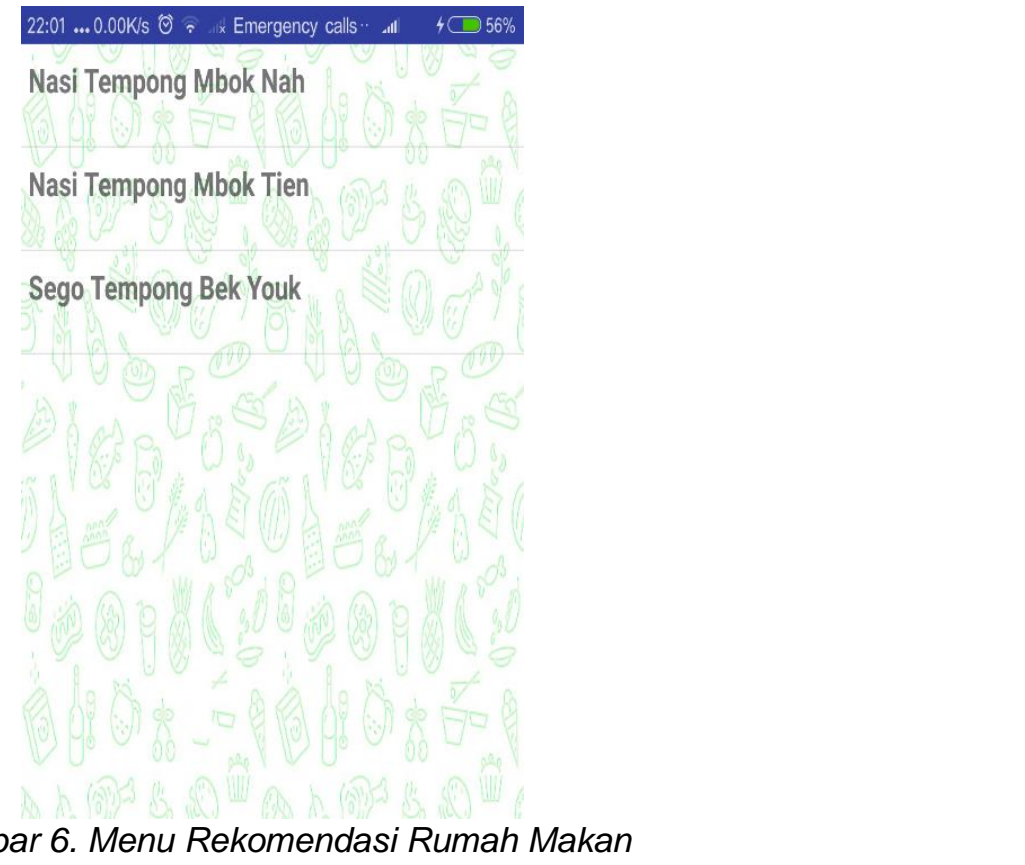

REPOSITOR, Vol. 2, No. 2, Februari 2020: 145-154 


\subsubsection{Tampilan Menu Lokasi}

Menu Lokasi pada Gambar 7 ini menampilkan letak dari Rumah Makan. Pada menu ini, Rumah Makan ditampilkan dalam bentuk icon serta menampilkan posisi kita berada. Ketika user menekan pada tombol icon yang dipilih akan muncul nama Rumah makan. Untuk menuju lokasi yang diinginkan, user menekan icon maka akan ditampilkan rute yang dituju.

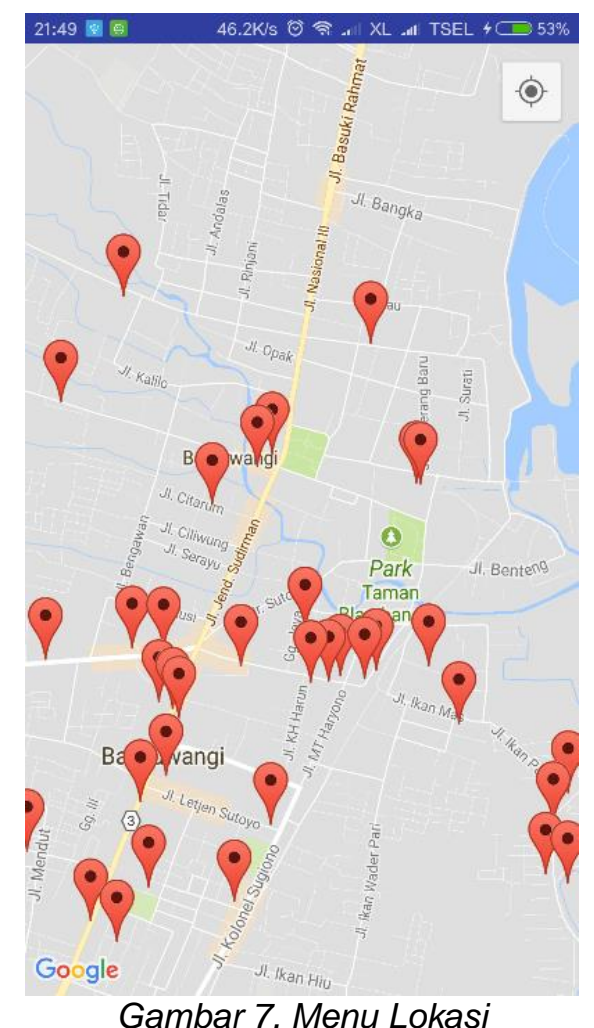

\section{Pengujian}

Pengujian dilakukan bertujuan mengetahui seberapa jauh berjalannya sebuah program atau keakuratan dari fungsi aplikasi. Selain itu, pengujian bertujuan mengevaluasi program dan perbaikan program untuk kedepannya.

\subsection{Pengujian Akurasi Sistem}

Untuk menguji proses kinerja sistem maka akan disajikan beberapa contoh data testing yang akan dihitung kedekatannya dengan data training. Dengan asumsi user telah memasukkan data testing sesuai dengan harga daan kategori yang dicari, maka proses perhitungannya seperti pada Tabel 1.

Tabel 1. Hasil Pengujian

\begin{tabular}{|c|c|c|c|c|}
\hline \multirow{2}{*}{ No } & \multirow{2}{*}{$\begin{array}{c}\text { Harga dan } \\
\text { Kategori }\end{array}$} & \multicolumn{2}{|c|}{ Rekomendasi } & \multirow{2}{*}{ Kesimpulan } \\
\hline & & Sistem & Manual & \\
\hline 1 & $\begin{array}{c}16000, \text { X22 } \\
\text { X23, X24 }\end{array}$ & $\begin{array}{c}\text { Mie Nyonyor, Mie Nyonyor } \\
\text { Pahlawan }\end{array}$ & $\begin{array}{l}\text { Mie Nyonyor, Mie } \\
\text { Nyonyor Pahlawan }\end{array}$ & Cocok \\
\hline 2 & $\begin{array}{c}15000, \times 7, X 12 \\
X 13\end{array}$ & $\begin{array}{c}\text { Warung 90s, Taichan } \\
\text { Jepun }\end{array}$ & $\begin{array}{l}\text { Warung 90s, Taichan } \\
\text { Jepun }\end{array}$ & Cocok \\
\hline 3 & $\begin{array}{c}20000, X 3, X 11 \\
X 12, X 19\end{array}$ & $\begin{array}{l}\text { Bakso Solo, Bakso Cak } \\
\text { agus, Warung Nanik }\end{array}$ & $\begin{array}{l}\text { Bakso Solo, Bakso Cak } \\
\text { agus, Warung Nanik }\end{array}$ & Cocok \\
\hline 4 & $\begin{array}{c}18000, X 17 \\
\times 18, \times 19, \times 20 \\
\text { X21, X22 }\end{array}$ & $\begin{array}{c}\text { Conato, Sego Cawuk } \\
\text { Rizky, Java Sunrise Cafe }\end{array}$ & $\begin{array}{c}\text { Conato, Sego Cawuk } \\
\text { Rizky, Java Sunrise } \\
\text { Cafe }\end{array}$ & Cocok \\
\hline
\end{tabular}




\begin{tabular}{|c|c|c|c|c|}
\hline 5 & $15000, X 1, X 2$ & $\begin{array}{l}\text { Warung Soto Ayam Pak } \\
\text { Slamet, Rawon Bik Ati }\end{array}$ & $\begin{array}{l}\text { Warung Soto Ayam } \\
\text { Pak Slamet, Bakso } \\
\text { Solo }\end{array}$ & Tidak cocok \\
\hline 6 & $\begin{array}{c}12000, X 16 \\
X 17, X 18, X 19\end{array}$ & $\begin{array}{l}\text { Sego cawuk rizky, warung } \\
\text { mbok jah, warung nanik }\end{array}$ & $\begin{array}{l}\text { Sego cawuk rizky, } \\
\text { warung mbok jah, } \\
\text { Warung Nanik }\end{array}$ & Cocok \\
\hline 7 & $\begin{array}{c}23000, X 3, X 4 \\
x 8, X 9, X 13 \\
X 14\end{array}$ & $\begin{array}{c}\text { Manizku, Warung Kepiting, } \\
\text { Pondok Bambu }\end{array}$ & $\begin{array}{l}\text { Manizku, Warung } \\
\text { Kepiting, Pondok } \\
\text { Bambu }\end{array}$ & Cocok \\
\hline 8 & $\begin{array}{c}18000, X 1, X 6 \\
X 11\end{array}$ & $\begin{array}{l}\text { Resto gama, Soto Ayam } \\
\text { Barokah P.H. Niti, Warung } \\
\text { Soto Pak Slamet }\end{array}$ & $\begin{array}{c}\text { Resto gama, Soto } \\
\text { Ayam Barokah P.H. } \\
\text { Niti, Warung Soto Pak } \\
\text { Slamet }\end{array}$ & Cocok \\
\hline 9 & $\begin{array}{c}14000, \times 15 \\
\times 22, \times 25, \times 26\end{array}$ & $\begin{array}{l}\text { Warung Mbok Nung, } \\
\text { Martabak D'Plong, Pecel } \\
\text { Rawon Mbok Sumi }\end{array}$ & $\begin{array}{c}\text { Warung Mbok Nung, } \\
\text { Martabak D’Plong, } \\
\text { Pecel Rawon Mbok } \\
\text { Sumi }\end{array}$ & Cocok \\
\hline 10 & $\begin{array}{c}17000, \times 2, X 7 \\
\times 12\end{array}$ & $\begin{array}{c}\text { Sate pak Wawan, Sate } \\
\text { Pak Untung }\end{array}$ & $\begin{array}{c}\text { Sate pak Wawan, } \\
\text { Bakso Solo, Bakso Cak } \\
\text { Agus }\end{array}$ & Tidak Cocok \\
\hline 11 & $\begin{array}{l}12000, X 21 \\
\text { X23, X28 }\end{array}$ & $\begin{array}{c}\text { Serabi Tuan, Depot } \\
\text { Kharisma }\end{array}$ & $\begin{array}{c}\text { Serabi Tuan, Depot } \\
\text { Kharisma }\end{array}$ & Cocok \\
\hline 12 & $\begin{array}{c}1500, \times 25, \times 27 \\
\times 28, \times 29\end{array}$ & $\begin{array}{c}\text { Depot Sarinadi, R.M } \\
\text { Salero Minang, Martabak } \\
\text { D'Plong }\end{array}$ & $\begin{array}{l}\text { Depot Sarinadi, R.M } \\
\text { Salero Minang, } \\
\text { Martabak D'Plong }\end{array}$ & Cocok \\
\hline 13 & $\begin{array}{c}13000, X 23 \\
\times 24, \times 25, X 26 \\
\times 28\end{array}$ & $\begin{array}{l}\text { Mie Nyonyor Pahlawan, } \\
\text { Warung Mbok Nung, } \\
\text { Depot Sarinadi }\end{array}$ & $\begin{array}{l}\text { Mie Nyonyor Pahlawan, } \\
\text { Warung Mbok Nung, } \\
\text { Depot Sarinadi }\end{array}$ & Cocok \\
\hline 14 & $10000, X 17, X 19$ & $\begin{array}{c}\text { Warung Mbok Jah, Sego } \\
\text { Cawuk Rizky }\end{array}$ & $\begin{array}{l}\text { Warung Mbok Jah, } \\
\text { Sego Cawuk Rizky }\end{array}$ & Cocok \\
\hline 15 & $\begin{array}{l}19000, X 1, X 2 \\
X 3, X 6, X 7, X 8\end{array}$ & $\begin{array}{l}\text { Warung Soto Ayam Pak } \\
\text { Slamet, Warung Pak } \\
\text { Salem, Resto Gama }\end{array}$ & $\begin{array}{l}\text { Warung Soto Ayam } \\
\text { Pak Slamet, Resto } \\
\text { Gama, Soto ayam } \\
\text { barokah p.h. niti }\end{array}$ & Cocok \\
\hline 16 & $14000, X 18, X 26$ & $\begin{array}{l}\text { Pecel Pangklang, Pecel } \\
\text { Rawon Mbok Sumi, } \\
\text { Pesantogan Kemangi }\end{array}$ & $\begin{array}{l}\text { Pecel Pangklang, Pecel } \\
\text { Rawon Mbok Sumi, } \\
\text { Pesantogan Kemangi }\end{array}$ & Cocok \\
\hline 17 & $\begin{array}{c}9000, \times 16, X 21 \\
\text { X25 }\end{array}$ & $\begin{array}{l}\text { Martabak D'Plong, Sego } \\
\text { Tempong bek youk }\end{array}$ & $\begin{array}{l}\text { Martabak D'Plong, Nasi } \\
\text { Tempong Mbok Tien, } \\
\text { Warung Mbok Nung }\end{array}$ & Tidak Cocok \\
\hline 18 & $15000, X 28, X 29$ & $\begin{array}{l}\text { Depot Sarinadi, Selang } \\
\text { Seling, Ampera Ayah }\end{array}$ & $\begin{array}{l}\text { Depot Sarinadi, Selang } \\
\text { Seling, Ampera Ayah }\end{array}$ & Cocok \\
\hline 19 & $\begin{array}{c}20000, X 1, X 2 \\
\times 3, X 4\end{array}$ & $\begin{array}{l}\text { Warung Soto Ayam pak } \\
\text { Slamet, Warung Pak } \\
\text { Salem, Manizku }\end{array}$ & $\begin{array}{l}\text { Warung Soto Ayam pak } \\
\text { Slamet, Warung Pak } \\
\text { Salem, Manizku }\end{array}$ & Cocok \\
\hline 20 & $10000,19,25,26$ & $\begin{array}{l}\text { Warung Nanik, Warung } \\
\text { Mbok Nung, Rujak Soto } \\
\text { Mbok Sun }\end{array}$ & $\begin{array}{c}\text { Warung Nanik, Warung } \\
\text { Mbok Nung, Rujak Soto } \\
\text { Mbok Sun }\end{array}$ & Cocok \\
\hline
\end{tabular}

Pengujian aplikasi dapat dihitung dengan perhitungan akurasi untuk mendapatkan nilai bobot yang akurat seperti pada Persamaan 1 .

Nilai akurasi $=\frac{\text { jumlah data akurasi }}{\text { jumlah seluruh data }} \times 100 \%$

Nilai akurasi $=\frac{17}{20} \times 100 \%=85 \%$ 
Berdasarkan uji akurasi sistem, didapat bahwa hasil akurasi sistem memiliki tingkat akurasi sebesar $85 \%$.

\section{Kesimpulan}

Dari hasil implementasi dan pengujian yang telah dilakukan pada bab sebelumnya dapat disimpulkan bahwa aplikasi yang dirancang dapat merekomendasikan rumah makan berdasarkan harga dan kategori makanan yang dipilih. Hal tersebut dapat dibuktikan pada hasil pengujian yang telah dilakukan.

\section{Referensi}

[1] M. A. Adipradana dan A. Pertiwi, "Prototype Sistem Rekomendasi Rumah Makan Menggunakan Metode K-Nearest Neighbour Berbasis Web," Univ. Dian Nuswantoro Semarang, 2015.

[2] Arif Akbarul Huda, Bimo Sunarfri Hantono, dan Widyawan, "Sistem Rekomendasi Restoran Dengan Pendekatan Ekstraksi Fitur Rasa Pada Menu Makanan," Univ. Gadjah Mada, Mar 2015.

[3] Andy Zico Eka Prasetya Sibuea, "Sistem Rekomendasi Tempat Makan Di Daerah Istimewa Yogyakarta Menggunakan Metode Kolaboratif," Universitas Atma Jaya Yogyakarta, 2015.

[4] Herdi Hari Susanto, "Implementasi Sistem Rekomendasi Pariwisata Semalang Raya Menggunakan Algoritma K-Nearest Neighbor," Universitas Muhammadiyah Malang, 2015.

[5] R. I. Ndaumanu dan A. M. Kusrini, "Analisis Prediksi Tingkat Pengunduran Diri Mahasiswa dengan Metode K-Nearest Neighbor," 2014.

[6] K. T. Martono dan O. D. Nurhayati, "Implementation of android based mobile Learning application as a flexible learning Media," Int J Comput Sci Issues IJCSI, vol. 11, no. 3, hal. 168, 2014.

[7] Mochamad Syamsul Ramdhani, "Sistem Informasi Geografis Merchant Bank Bni Kanwil Jawa Barat Berbasis Android," Universitas Widyatama Bandung, 2016.

[8] Svennerberg Gabriel, Beginning Google Maps API 3. United States of America, 2010.

[9] S. W. Kusumaningati, "Pengembangan Sistem Informasi Kartu Menuju Sehat Sebagai Alternatif Pengelolaan Posyandu Secara Digital," PhD Thesis, UNY, 2015.

[10] Chasseur, Craig., Li, Y. dan Patel, Jm, "Enabling JSON Document Stores in Relational Systems," Sixt Int Workshop Web Databases, 2013. 
REPOSITOR, Vol. 2, No. 2, Februari 2020: 145-154 